\title{
Rasgos de continuidad del gallego en documentos del monasterio de San Andrés de Espinareda (León) en el siglo XIII ${ }^{1}$
}

\author{
Galician continuity in documents of San Andrés de Espinareda (Bierzo, León) \\ in the 13th Century
}

Patricia Giménez Eguíbar

Western Oregon University (Estados Unidos)

gimenezp@wou.edu

M. ${ }^{a}$ Nieves Sánchez González de Herrero

Universidad de Salamanca / IEMYRhd (España)

dimes@usal.es

Recibido: 31/01/2019

Aceptado: 12/06/2019

\section{Resumen}

La finalidad de este trabajo es exponer una serie de rasgos lingüísticos contenidos en documentos notariales del siglo XIII, custodiados en el monasterio de San Andrés de Vega de Espinareda (El Bierzo, León), que muestran, en distinto grado, la continuidad del gallego en el registro escrito y su convivencia con soluciones del asturianoleonés occidental, comunes en ocasiones, diferentes otras veces. Hemos seleccionado rasgos pertenecientes a los niveles graficofonético, morfosintáctico y léxico, puesto que en los tres puede observarse la continuidad. Se trata de un análisis básicamente descriptivo, a partir de los datos que ofrecen los testimonios manejados, datos que se comparan con los que conocemos para las variedades lingüísticas del entorno geográfico más próximo en la Baja Edad Media. A partir de esta comparación se pone de manifiesto la distribución geográfica de las voces y rasgos estudiados, que muestran diferencias, con distintos grados de extensión y, en definitiva, prueban la existencia del continuo dialectal y la falta de fronteras lingüísticas nítidas entre las variedades colindantes.

\section{Palabras clave}

lingüística histórica; dialectología; contacto de lenguas; gallego; leonés.

\section{Sumario}

1. Introducción 2. Corpus documental 3. Análisis lingüístico 3.1. Análisis gráfico-fonético 3.1.1. l / ll 3.1.2. ch / x 3.1.3. it-yt / ch y (u)it 3.1.4. Otros 3.2. Análisis morfosintáctico 3.2.1. Infinitivos conjugados 3.2.2. Pronombre sujeto de primera persona singular: eu / you / yo 3.3. Análisis léxico 3.3.1. Léxico de la descripción del espacio 3.3.2. Léxico de la vida cotidiana 3.3.3 Léxico jurídico 3.3.4. Occidentalismos fonéticos 4 . Conclusiones.

\section{Abstract}

The aim of this article is to explain a series of linguistic features contained in notarial documents of the 13th century from the monastery of San Andrés de Vega de Espinareda (El Bierzo, León), which show, to varying degrees, the continuity with Galician language in the written register and with Western Asturian and Leonese linguistic variety. We have chosen a variety of linguistic features: from the phonetical, morphosyntactic and lexical point of view, since in the three level the continuity with Galician language can be observed. It is a descriptive analysis, based on the data offered by the testimonies handled, data that are compared with those we know for the linguistic varieties of the closest geographical environment in the Late Middle Ages. From this comparison, the geographical distribution of the voices and traits studied is shown, which show differences, with different degrees of extension and, in short, prove the existence of the dialectal continuum and the lack of clear linguistic boundaries between the neighboring varieties.

\section{Key words}

Historical Linguistics; Dialectology; Dialect Contact; Galician; Leonese.

\section{Contents}

1. Introduction 2. Corpus 3. Linguistic Analysis 3.1. Phonetic Analysis 3.1.1. l/ ll 3.1.2. ch / x 3.1.3. it-yt / ch y (u)it 3.1.4. Others 3.2. Morphosyntax Analysis 3.2.1. Conjugated infinitives 3.2.2. First Person Subject Pronoun: eu / you / yo 3.3. Lexical Analysis 3.3.1. Spatial Lexical Items 3.3.2. Daily Life Vocabulary 3.3.3 Legal Terms 3.3.4. Western Phonetic Words 4. Conclusions. 


\section{Introducción}

Como hemos intentado reflejar en el título, nuestra intención no es abordar el Uestudio de la documentación de San Andrés de Espinareda relacionando hechos lingüísticos y su contexto geográfico, al menos no de manera exclusiva ni excluyente, sino ocupándonos más bien de la «extensión y distribución geográficas de fenómenos particulares [...] dentro de una o más comunidades, y de los límites entre las áreas ocupadas por tales fenómenos, los cuales solo en casos especiales pueden coincidir con los límites de la lengua o lenguas estudiadas» (Gimeno Menéndez 1993, apud Dubert 2018: 7).

El monasterio de San Andrés de Espinareda se fundó y se halla situado en el Bierzo, León, en el curso medio del río Cúa, es decir, en una zona lingüística que podría considerarse de transición, en el continuo dialectal peninsular norteńo; en este caso concreto hablamos de transición entre el gallego y el leonés occidental, tal y como han mostrado con datos del siglo xx Seco Orosa (2001: 92-93) y Marcet Rodríguez (2001: 271-273 y 2002: 450-451)2.

Esta situación de contacto y paso entre dos variedades lingüísticas sin fronteras nítidas perceptibles en el siglo pasado merece alguna consideración previa al análisis de testimonios escritos en la zona en el siglo XIII.

Entre los hechos que damos por sentados en la historia de las variedades peninsulares están las dificultades para establecer fronteras claras entre las variedades surgidas del latín en la Edad Media, la posibilidad de intercomprensión o inteligibilidad entre ellas y la falta de homogeneidad lingüística en el interior de los distintos reinos; a ello podríamos sumar una situación de plurilingüismo existente en cortes y ciertos núcleos urbanos (Moreno Fernández 2005: 82; García Martín 2008: 34, entre otros). En este sentido resulta muy clara la siguiente afirmación de Moreno Fernández (2005:

1. Este trabajo está relacionado con el proyecto: Variación Lingüística en la documentación de Castilla y León. II. Los Documentos de Mombeltrán (Ávila). Edición y Estudio, financiado por el Ministerio de Economía y Competitividad. Dirección General de Investigación: FFI2014-57615-P. Agradecemos sinceramente a los revisores del artículo las sugerencias aportadas, que, sin duda, han contribuido a su mejora; también a Ricardo Pichel Gotérrez, de la Universidad de Alcalá, por brindarnos orientación, materiales y su generoso tiempo.

2. Recogemos la aportación de trabajos de geografía lingüística porque se trata de una disciplina y un planteamiento que aporta datos importantes para el conocimiento histórico de las variedades. Con un enfoque histórico también y abundantes datos toponímicos del Bierzo, García y García (1997: 20) concluye que la divisoria entre el gallego y el asturianoleonés en el Bierzo no es brusca ni está claramente definida sino que viene marcada "por una franja comprendida entre ambas vertientes del río Cúa hasta su desembocadura en el Sil y que se continúa hasta el Cabrera”. Por su parte Fernández Rei (2002: 327) considera que Veiga de Espinareda es uno de los diecinueve concejos occidentales leoneses en los que se habla total o parcialmente gallego. En el trabajo citado de este autor, pueden consultarse noticias sobre la situación del gallego en el Bierzo a finales del siglo xx y comienzos del actual, sobre su reintroducción y sobre la conciencia sociolingüística de los habitantes de la zona. 
82): «Cada territorio reunía elementos diferentes que se conjugaban de modo diverso para la creación de los nuevos instrumentos lingüísticos, por más que muchos de esos elementos fueran compartidos».

Si nos centramos en la consideración de variedades escritas próximas entre sí y más concretamente en los límites escripto-lingüísticos de dos variedades vecinas como la gallega y la leonesa, es fácil comprobar que en estudios previos se ha puesto de manifiesto la problemática delimitación entre áreas de Galicia limítrofes con las que continúan en las actuales provincias de León y Zamora. Souto Cabo (2008: 171), por ejemplo, afirma que el debate puede surgir en primer lugar a la hora de definir, desde un punto de vista idiomático, la producción emanada de los monasterios de Castañeda (Calende), Carracedo (Carracedelo) y San Pedro de Montes (Ponferrada):

Mesmo sendo a língua funcional destes espazos xeográficos unha variedade oriental do galego, a scripta utilizada no período obxecto da nosa análise revela un claro influxo dos modelos leoneses vicińos. Face à prática normal no conxunto galego-portugués, rexistamos, entre outras, características como: (i) conservazón gráfica de -N- e -L- intervocálicos latinos (xeral); (ii) ditongazón de $\breve{\mathrm{E}}$ breve latino (ocasional); (iii) formas verbais irregulares (tenga, venga, etc.) de configurazón allea às pautas evolutivas galego-portuguesas (frecuente) [...] Do anterior surxe a identificazón dun conxunto documental a que atribuímos a etiqueta de «documentos galaico-leoneses», grupo formado maioritariamente por cartas producidos nesa área (castellano-)leonesa e en menor medida nos espazos políticos galego e portugués

$\mathrm{Al}$ margen de los fenómenos que consideremos en cada caso, la situación de los testimonios que vamos a analizar a continuación ofrece en líneas generales idénticas mezclas o interferencias, de modo que también aquí podríamos utilizar la etiqueta de «documentos galaico-leoneses».

\section{Corpus documental}

Nuestro análisis se basa en los testimonios contenidos en la edición llevada a cabo por Jiménez Suárez (2005), que va de 1043 a 1428. Consideramos que dicha edición, así como la colección en la que se inserta, reúne la fiabilidad y calidad suficientes como para ser objeto de un estudio lingüístico; no obstante, esperamos consultar pronto los originales, lo que hasta ahora no ha sido posible.

El trabajo mencionado contiene la edición íntegra de los documentos conservados, en original o copia, hasta el año 1300; del resto, hasta 1428, consta únicamente el regesto $^{3}$. Son 73 testimonios hasta 1298 , sumando originales y copias, con inclusión

3. La práctica totalidad de la documentación conservada hoy se halla depositada en dos secciones diferentes del Archivo Histórico Nacional de Madrid. Dentro de la sección de Clero, en el apartado 
de documentos de cancillería. Entre los 73 hay 20 copias, algunas de cancillería real, copias que eliminamos en su totalidad, porque desde el punto de vista filológico interesan los originales, de manera que nos quedamos con 53. De 1043 a 1244 contamos con 14 documentos de los cuales 4 son copias mientras que los otros diez, originales, están redactados siguiendo la norma latina medieval ${ }^{4}$; es decir, basamos nuestro estudio en 43 documentos originales datados entre 1253 y $1294^{5}$ y escritos en romance, o, al menos, con partes de la dispositio en romance 6.

\section{Análisis lingüístico}

Vamos a dividir la exposición en tres bloques diferentes que se refieren a aspectos gráfico-fonéticos en primer lugar, morfológico-sintácticos a continuación y finalmente léxicos; en todos los casos hemos hecho una selección de fenómenos y vocablos, centrándonos en algunos de los que muestran la continuidad, de manera total o parcial, con el gallego.

\subsection{Análisis gráfico-fonético}

\subsection{1. $l / l l$}

La revisión de las grafías $l / l l$ afecta al tratamiento de las evoluciones de consonantes y grupos consonánticos que habitualmente se tienen en cuenta para marcar diferencias entre las variedades observadas y caracterizar su descripción; es el caso, entre otros, de los resultados de L- inicial latina, /l/ en gallegoportugués y castellano, frente a $/ \mathrm{j} / / \mathrm{K} /$ en asturianoleonés, o de -LY- y grupos análogos, $/ K /$ en gallegoportugués, /j/,/K/ en asturianoleonés y/dz/ en castellano (Lleal 1990: 186-188 y Vázquez Diéguez 2018: 133).

Como resultado de L- los documentos de Espinareda ofrecen de manera

de pergaminos, se localizan 239 pergaminos que corresponden al periodo estudiado (Jiménez Suárez 2005: 21).

4. Podemos utilizarlos para estudio del léxico pero aquí no los consideraremos para el análisis gráfico-fonético ni morfológico-sintáctico.

5. Los dos posteriores, con data cronológica 1297 y 1298, son copias. Somos conscientes del carácter limitado del corpus que, no obstante, juzgamos suficiente y válido para este primer acercamiento lingüístico.

6. Incluimos en este estudio el documento número 15, fechado en 1253, en cuya dispositio podemos leer "quanta hereditate nos pertenece de don Ysidro, que fu mio marido [...] de la gram cousa ata la pechena", en medio de largas fórmulas latinas medievales. Sería la única excepción porque a partir de 1256 (doc. 17), la escritura es plenamente romance. 
sistemática grafía $l^{7}$ : laurardes, lauralla, leyxardes, leyxedes, lauorias, liures, liurassem, lagar, logo, lugar, lugar, leuou, legume, lee 'ley', lino ${ }^{8}$, etc. Recordemos de momento que, a pesar de la alternancia $/ / l l$ en posición interior y como resultado de orígenes diversos, la representación gráfica de la palatalización leonesa de L- es tardía y prácticamente ausente en el siglo XIII (Morala 2004: 559 y 565).

En cambio, para -LY- es fácil encontrar alternancia $l / l l$, si bien en conjunto predomina ll: muller, más raro moller, fillo, mellor, eruellas, aconsellamos, collirmos 'cogeremos', allenerdes, 'ajenaréis', consello, palleyro, etc., junto con muler, filo, fila, melor, conzelo, calela, etc. Grafía minoritaria es $y$, presente cuatro veces en la palabra conceyo en un documento de 1270 en el que melor aparece grafiado con $l$, y conseyo, en otro de $1273^{9}$.

Vamos a analizar estos datos con más detenimiento.

Desde el punto de vista cronológico, la alternancia $/ / l l$ va desde los primeros testimonios hasta 1289, es decir, se extiende a lo largo del siglo xiIr. No siempre un documento presenta grafías regulares: así, en uno de 1286, en el que figura como notario Martin Iohanes, se hallan fillos e fillas junto a concelo; en otro de 1289 con Domingo Garçia, que se intitula "notario público de Cacauellos», predomina $l l$, filla, collirmos, consello, allenerdes, y alternan mellor y melor ${ }^{10}$. Más frecuente es que $l$ resultado de -LY- alterne en el mismo testimonio con $l l$ resultante de otros grupos: en 1270 alternan en el mismo documento muler, celleyro y Castella. La palabra Castella en concreto, presente con frecuencia en el protocolo final, presenta $l l$ incluso en los testimonios que escriben muler, filo, conzelo o melor de manera exclusiva; además de Castella, en estos casos podemos encontrar dello o villa y análogos. Uno de los primeros documentos plenamente romance, fechado en 1256, ofrece muler, uasalos, galinas y Castella, lo que muestra la regularidad gráfica con la que se transmite esta palabra en el corpus de Espinareda.

Si consideramos los usos de cada notario, observamos ciertas preferencias sin que

7. Encontramos algún caso aislado de $l l$-en formas del artículo o del personal átono, lla metade, se llo disséssemos, quelle dieran, que quedan al margen de momento. En todos los fenómenos que tratamos hablaremos de soluciones mayoritarias, dominantes o minoritarias, aisladas, porque consideramos que en un corpus de pequeño dominio y con estas características carecen de valor las cuantificaciones. No vamos a ocuparnos en esta ocasión de las alternancias gráficas existentes en artículos, pronombres átonos y en los casos de asimilación de preposición más artículo, porque su consideración rebasaría los límites del presente trabajo.

8. En los apartados del análisis gráfico-fonético, no indicamos el documento en el que aparece cada uno de los ejemplos porque el listado se alargaría mucho y porque en cada fenómeno señalamos a qué escribano se deben las formas, ya que consideramos que es el dato más significativo.

9. No incluimos la grafía $i$, presente en un único documentado, de 1276 que nos llega en un traslado notarial de 1433, que escribe fiio, fiios sobredichos.

10. En el documento número 21 de la colección, incompleto, sin fecha ni notario, alternan muler, muller y fillo. 
impliquen en todos los casos usos sistemáticos. Uno de los más regulares es Martinus ${ }^{11}$, que en testimonios fechados en 1256, 1266 y 1273 , usa $l$ para representar el resultado de -LY-, aunque regularmente escribe Castella, voz en la que $l l$ tiene distinto origen pero con presumible confluencia de resultados. También muestra preferencia por la grafía $l$ para -LY- Martín Iohanes, «notario público del abbat de Sant Andres enos coutos», en siete testimonios que van de 1272 a 1287 , en los que no faltan ejemplos de muller, alternancias de pela y pella en el mismo documento o de vila / uillas en otros. Pedro Pérez, "públicu notario del conzelo de Ponfferrada», es responsable de tres testimonios entre 1264 y 1283 , en los que recurre a $l y l l$ para grafiar el resultado de -LY-. En cuanto a Domingo García, «público notario de Cacauellos», presenta en dos testimonios ${ }^{12}$ alternancia $l / l l$, con predominio de $l l$, tanto para el resultado de -LY- como para el de -L- o -LL-: muller, filla, melor, consello, uasallos o sollo 'suelo'. Es más significativo el número de notarios en cuyos testimonios se emplea $l l$ para -LY-; es el caso de Pedro Aparicio, «notario público de Cacauellos» al menos de 1281 a 1286, y de Pedro González o Gonçálvez, también «público notario de Cacauellos» en testimonios que van de 1270 a 1276. En 1280 suscribe un documento como «notario público de Cacauellos» Fernán González en el que registramos también muller y mellor, pero no contamos con más testimonios de este notario. Sucede lo mismo con otros notarios en los que el empleo de $l l$ para el resultado de -LY- es exclusivo; su escasa representación, uno o dos documentos, no permite ir más allá de la afirmación del uso de $l l$ en uno o dos testimonios; es el caso de Iohan Domínguez, que en 1274 escribe "por mandado d'Esteuan notario público del rey en Uillafranca», o de Iohan Miguéllez, «notario del rey en Uillafranca» en 1290.

Como acabamos de señalar, solo dos de los testimonios presentan la grafía $y$ para representar el resultado de -LY-. El primero de ellos, fechado en 1270, está validado por Salvador Pérez, "público notario del conceyo de Bienuibre» y repite en cuatro ocasiones la palabra conceyo, sin contener ninguna otra del mismo origen. El segundo, de 1273, debido a Iohan Payz, "público notario de la iglesia de Astorga», escribe conseyo, que es la única palabra en la que se muestra el resultado de -LY-.

Nos parece bastante claro que, por lo que se refiere a la evolución de -LY-, la alternancia gráfica $l / l l$ nos muestra el resultado palatal lateral coincidente con el gallego y portugués ${ }^{13}$. Resulta significativa la sistematicidad de las grafías $l y l l$, que alternaron

11. Valida siempre el documento con "Martinus notuit" sin más especificación.

12. No incluimos aquí aquellos en los que consta "Eu, Iohan Perez, tenente as ueçes de Domingo Garçia público notario de Cacauellos, a rogo de los sobreditos fuy presente e o escriui”. En este caso hallamos también alternancia de grafías $/ / l l$ para representar el resultado de la consonante y grupos señalados en la notaría de Domingo García; muller, mellor, calela, sollo 'suelo', uolluntade, uasalos/ uassallos, caualeyro/caualleyro, etc.

13. Marcet (2007: 985) señala que, en la representación de los resultados de -LY-, las grafías de la tradición gallega, $l$ y $l$, cuentan con una presencia notoria en las escribanías más occidentales de Carrizo, con claro predominio de la grafía simple sobre la doble, "en lo que sin duda hay que ver una 
con diferente frecuencia en el siglo XIII con valor alveolar y palatal en distintas zonas peninsulares, con más intensidad en documentación de procedencia leonesa, y especialmente en la más occidental, que en los escritos castellanos (Marcet 2007: 687 y Sánchez Prieto-Borja 2004: 439) ${ }^{14}$. Es igualmente significativa la escasísima presencia de $y$, la grafía característica de la documentación leonesa que se afianza especialmente a finales del XIII (Morala 2004: 558). El hecho de que aparezca en solo dos testimonios en los que figuran notarios de Bembibre y Astorga, al oriente ya de Vega de Espinareda, especialmente el segundo, parece indicar que Vega de Espinareda se hallaba en el área leonesa en la que continuaba el resultado gallego de -LY-

No es posible, en cambio, a pesar del carácter sistemático de la grafía $l$, interpretar el valor alveolar o palatal de la evolución de L-, en coincidencia con el gallego o con el leonés respectivamente, porque es la grafía utilizada más habitualmente en el siglo XIII en asturianoleonés, variedad en la que sí se produjo la palatalización (Marcet 2007: 603-612; Morala 2004: 565; García Arias 1995: 630-631) ${ }^{15}$.

nueva influencia de la tradición escrituraria gallego-portuguesa o, más bien, una continuación de los usos escriturarios occidentales". No obstante, en el conjunto de los testimonios de Carrizo en el siglo XIII predomina $y$ (con una frecuencia en términos porcentuales absolutos del 61'77\%), acorde con la norma escrituraria leonesa. Para el resultado $/ K /$ en gallego y portugués de -LY-, -C'L- y -G'L-, cfr. Ferreira \& Osorio (2008: 51) y Lleal (1990: 218). Con relación a este rasgo a finales del siglo xx, tal y como recogió Cano González (1998: 19 y mapa 3), a partir de datos del Atlas Lingüístico de El Bierzo, la solución $/ K /$, coincidente con el gallego, ocupaba aproximadamente la mitad occidental de El Bierzo.

14. Recordamos que, en el caso concreto del asturiano, que en el período medieval representa habitualmente los resultados de -LY-, -C'L- y -G'L- mediante $l l$, coincidiendo con los de -LL- y L-, García Arias (1995: 631) afirma que "de esta conducta gráfica se sigue una confusión que no responde a la situación fonológica medieval ya que todo el asturiano distingue plenamente, todavía en la actualidad, los resultados de $l-,-l l-\mid l j, c^{\prime} l, g^{\prime} l$, aunque esto debiera ser más matizado al hablar de territorios occidentales al sur de la Cordillera". Al referirse a la situación de León señala que "parece que, al menos desde el s. XII, empieza a generalizarse $y$ (conceyo, fiyo) y se da un intento diferenciador" y recuerda que $y$ es la grafía mayoritaria en el Fuero de Zamora, seguida por $l l$, o que la documentación de Carrizo muestra preferencia por $y$ desde 1242, aunque $l$ todavía es frecuente en alguna palabra a finales del siglo.

15. Como se puede comprobar en algunas colecciones documentales, entre ellas la de Carrizo (Casado Lobato 1983), por ejemplo, hay algún caso de $l l$ - inicial en la segunda mitad del siglo XIII (Lleon, 1260; llugar, 1264; llugar o Llorienço, 1283), pero son absolutamente minoritarios en comparación con $l$-. En los testimonios de Gradefes (Burón Castro), $l l$ - aparece únicamente en posición inicial en la representación de artículos y pronombres, en número escaso, si comparamos con $l$-, y en los antropónimos Llambla o Llainiz, alternando con Lainiz, en un documento de 1152 que sigue la norma latina. Marcet (2007: 603-604) pone de manifiesto la presencia mayoritaria de $\mathrm{l}$ - < L- en la documentación leonesa del siglo XIII, aunque recoge casos de $l l$ - que representan un porcentaje de uso del 2'56\% en Sahagún, un 1'43\% en León y un 1'97\% en Carrizo. Aporta, además, las siguientes observaciones: los documentos que presentan la grafía $l l$ - recurren también al empleo de $l$ - para representar L-, siendo $l$ - mayoritario. Los casos de $l l$ - se sitúan en la segunda mitad del XIII, afectan sobre todo a los nombres propios $y$, dentro de su escasa presencia, parecen más frecuentes en 


\subsection{2. $\operatorname{ch} / x$}

Aunque afecta a un número bastante limitado de palabras y, en consecuencia, los ejemplos no son muy abundantes, vamos a ver los resultados de la evolución de los grupos latinos PL-, KL- y FL-, que en los testimonios de Espinareda se representan generalmente con $c h$-y en un solo documento con $x$-. Recordemos que estos tres grupos confluyeron básicamente en $/ \mathfrak{t} /$ en gallegoportugués y en áreas asturianoleonesas occidentales próximas, $/ S /$ en parte del dominio leonés y $/ K /$ en zonas del occidente, en el centro y en el oriente de Asturias, en coincidencia con el castellano (Lleal 1990: 186; Vázquez Diéguez 2018: 134). Para el dominio asturianoleonés, en el que la isoglosa es compleja, expone Morala (2004: 558) que, mientras que al norte de la cordillera los resultados se reparten entre la africada $/ \mathrm{t} /$ del occidente (chano) y la palatal lateral $/ K /$ del centro y oriente (llano)

en las tierras de la Meseta es preciso identificar aún otro resultado más: una fricativa dorsopalatal sorda $/ s ̌ /(x a n o$ ), resultado de la desafricación de una /ĉl. Este fonema lo encontramos, con la esperable grafía x, en los textos leoneses incluso más allá de lo que probablemente fueron los límites de este resultado: xamados, xano, xumazo $[\ldots]^{16}$.

Los testimonios de San Andrés de Espinareda ofrecen bastantes ejemplos del verbo chamar < CLAMARE: chaman, al menos con nueve apariciones («iaz hu chaman Carral de Castro"; "ena uilla que chaman Chanedo"; "ena uilla que chaman el Faueyro", etc.), chamaua; y del verbo chantar < PLANTARE: chantedes, chantar ${ }^{17}$, chantado y un chantados, sustantivo, "con suos chantados liures e quitos»; hay además achar 'hallar' < AFFLARE y achasse. Un único documento recoge la grafía $x$ en «rogados e xamados», «xamado e rogado» y axaren; el testimonio, fechado en 1273, tiene como notario a Iohan Payz a quien ya hemos citado como «público notario de

la zona occidental (Carrizo) que en la central y oriental.

16. García Arias (1995: 631.632) interpreta que esta $x$, no desconocida en asturiano, pero más frecuente al sur de la cordillera, es una grafía de palatal sin más. Para el resultado $/ \mathfrak{g} /$, grafiado $c h$ en gallego y portugués, pueden verse, entre otros, Ferreira \& Osorio (2008: 54), Vázquez Diéguez (2018: 134) y Lleal (1990: 218).

17. En un documento de 1281 se hallan "damos a chantar" y más adelante "e deue della achantar de uinna”, donde posiblemente hay que interpretar también a chantar. Sobre los resultados de PL-, KL- y FL- en la documentación de Carrizo en el siglo XIII, Marcet (2007: 530) expone que, a pesar de ser la africada /ĉ/ característica de los dominios más occidentales del leonés y del gallegoportugués, en la documentación de Carrizo tiene poca representación, pues tan solo aparece registrada en seis documentos, y predomina la presencia de la fricativa $/ \check{s} /$. 
la iglesia de Astorga» a propósito de conseyo en uno de sus testimonios ${ }^{18}$. Frente a este uso de un notario de zona leonesa más oriental que Vega de Espinareda, muestran ch- los pertenecientes a las notarías de Martinus, Martín Iohanes, Pedro González, Pedro Aparicio y Iohan Pérez, que, como ya hemos visto a propósito de las grafías $l$ / $l l$, ejercen en Cacabelos o en el propio monasterio, con la excepción de Martinus, para quien no se especifica nada.

Parece pues razonable interpretar que también en este uso lingüístico Vega de Espinareda forma comunidad con los resultados gallegos, es decir que el resultado que caracteriza al gallegoportugués alcanza este lugar ${ }^{19}$. Y sobre los usos lingüísticos de los testimonios de Iohan Payz, recordemos que, a propósito de la documentación burgalesa, Torrens (2013: 327-328) ya señaló que la realidad diatópica-dialectal de un escrito no está ligada al lugar archivístico en el que se custodia sino al redactor y a su ámbito de formación escrituraria.

\subsection{3. it-yt / ch y $(u) i t$}

No son muchas las voces en las que se pueden observar los resultados de -KT- y -(u)LT- latinos, /jt/ en gallegoportugués (Vázquez Diéguez 2018: 133) y asturianoleonés occidental (García Arias 1995: 632), frente al castellano/ț/ (Lleal 1990: 186-188), aunque aquí contamos con la ventaja de que algunas de ellas se repiten con frecuencia. Son especialmente abundantes dito / dicho y sus compuestos sobredito, devandito $\mathrm{y}$, a veces escrito en un solo tramo, yadito, iadito ${ }^{20}$. En este caso dito, tal cual o formando parte de algún compuesto, cuenta con más de 150 apariciones, por una sola de sobredictos, con mantenimiento de -ct-, y solo tres de sobredicha(s), con $/ \mathfrak{y} /$. De estas tres últimas, una pertenece a un testimonio cuyo notario es Salvador Pérez, notario de Bembibre, en el que leemos también pecharía y fecha la carta. Menos esperables son las dos ocasiones en las que sobredicha(s) se halla en un mismo documento en el que consta como notario Pedro Aparicio, notario público de Cacabelos, cuando en el mismo testimonio leemos aproueytada ${ }^{21}$ y en otros de él mismo sobredita. Ciertamente el resultado/jt/ para-KT- en esta palabra en

18. Junto a usos gráficos de la tradición de escritura leonesa, como los mencionados conceyo o xamados, es este uno de los pocos testimonios de la colección de Vega de Espinareda que ofrece algún caso de pérdida de -n-, al repetir tres veces la palabra dieros por dineros.

19. La grafía $c h$ puede representar de manera aislada otros sonidos, como la oclusiva velar $/ \mathrm{k} /$ en pechena, "de la gram cousa ata la pechena", o, con interpretación más dudosa Choan, nombre propio que figura en documento de 1274, "Alcaydes, Choan Fernández e Apariciu Rudríguez”, que escribe también "Tereysa Sangez" y "a la uoz del rey peygi C marauedis".

20. Con suso, no encontramos susodito tal cual sino de suso dito, grafiado de distintas maneras, dessuso dito, desuso dito, etc.

21. Véase gallego profeitar, aprofeitar en documento medieval pontevedrés en DCECH, s.v. provecho. 
concreto no es ajeno al castellano medieval, donde convivió con dicho; sin embargo, es la proporción de /jt/ frente a / $/ \mathrm{g} /$ lo que aquí parece más significativo.

Otra palabra que aparece con relativa frecuencia, aunque a notable distancia de dito, es feyto, $-a$ / fecho, $-a$; su presencia en el protocolo final, en la fórmula feyta esta carta, o simplemente feyta seguida de la fecha, fecho fu esto y similares, explica esta frecuencia, aunque no es la única posibilidad, pues también aparece como sustantivo, este feyto, o, como participio, acompańando a distintos nombres, "un lagar feyto con todo sou aparellamiento", "los dineros branquidos que foron feytos quando se començou ela primera guerra de Granada», etc. En total, de las 37 apariciones de feyto $(s),-a(s), 27$ corresponden a la fórmula mencionada. Frente a estas 37, contamos con seis de fecho, - a; tres de ellas en la fórmula fecha la carta, más dos de fecho fu esto y la última, al margen del uso formulario, "dio una sentencia el deán sobredito fecha en esta manera». Uno de los usos corresponde a la notaría de Saluador Pérez, de Bembibre, de la que ya hemos señalado que usa $c h$ como resultado de -KT- y tres a Iohan Payz, notario de Astorga, cuyos usos, como ya hemos visto en otros rasgos, se apartan de los más habituales en Espinareda; en este, usa deuandito o sobredito, pero fecho, derechos o pechasse. Los dos restantes, ambos en la fórmula fecha (esta) carta, corresponden a Pedro Pérez, notario público de Ponferrada, que en distintos testimonios alterna los usos de $y t / c h$, con predominio del primero, y a Pedro Gonzáluez, notario de Cacabelos, que lo usa una sola vez en la fórmula cuando en el cuerpo del documento dice feyto o muyto. Comprobamos de nuevo la vinculación uso gráfico-notaría y añadimos la consideración de uso formulario.

Estas dos características dan también cuenta de otro empleo claramente formulario, el del verbo peytar / pechar, 'pagar' (DCECH, s.v. paz), usado con frecuencia en la sanctio de los documentos, en las cláusulas penales para quien no cumpla lo acordado ${ }^{22}$. En este caso tenemos veinte apariciones de $y t$, peyte, peytemos, peytar, por trece de ch, peche, pecharía, pechasse; estas últimas corresponden a los mismos notarios que acabamos de señalar para fecho, $-a$, a los que se suman Martinus, del que no tenemos ninguna referencia, y Martín Iohanes, notario del abad de San Andrés, si bien hay que destacar que los dos usan únicamente $c h$ como resultado de -KT- en pechar, y mantienen $y t$ en las demás palabras del mismo origen.

Un uso gráfico diferente que afecta a este verbo y que está presente en dos documentos de la notaría de Pedro Pérez, de Ponferrada, es peygi, peyge, donde puede interpretarse una lectura / jf /, atestiguada en otras fuentes occidentales coetáneas, como el Fuero de Zamora (Carrasco 1987: 199) y resultado conocido hasta el siglo

22. Nos referimos a contextos como los siguientes; "qual de las partes al outra parte esta carta passar ou britar peyte C marauedis a essa parte que recebir el torto e al rey peyte C marauedis en couto"; "e demays peyte a la uoz del rey por pena oytaenta e quatro marauedis"; "Quen esta carta queser britar al outra parte péchele $\mathrm{C}$ morabetinos, e al rey peche CC morabetinos en couto". 
xx en zonas de León (Borrego Nieto 2007: 145 y 148); parece apoyar esta lectura el hecho de que el mismo documento que escribe peygi, ofrezca Tereysa Sangez.

Continuadores del latín DĒRĒCTUS (DCECH, s.v. derecho) son dereyto(s), con nueve ocurrencias, y derecho, con cinco, tres de ellas en un mismo testimonio; cuatro se hallan en testimonios de la cancillería de Iohan Payz y uno en la perteneciente a Pedro Pérez.

Como continuadores de ŎCTO contamos con un octo, y con diez apariciones de oyto, más una del compuesto oytaenta, frente a un único caso de ocho; este uso de ocho es excepcional en la notaría de Iohan Domínguez ${ }^{23}$, que en el resto de voces del mismo testimonio procedentes de -KT- latino muestra la solución it / yt. Aunque no son muchas las apariciones de oyto, observamos que ninguna de ellas presenta diptongación de Ŏ, posible en leonés.

El resto de voces procedentes de-KT- ofrecen $y t$ como resultado pero en apariciones únicas: malfeytrias y malfeyterias, noyte, fruyta y el ya mencionado aproueytada ${ }^{24}$.

Finalmente, para -(u)LT- tenemos muito / muyto, que aparece en diez ocasiones en la fórmula que, con pequeñas variantes, sigue a la enumeración de testigos «E outros muytos que esto uirom e lo oyron", "outros omes muytos que uiron e que oyron», etc., a las que hay que sumar dos ocurrencias de "pouco e muito» y una de "por muyto amor e seruiçio», es decir, un total de trece frente a ninguna de mucho; precisamente las dos notarías en las que podía esperarse mucho, la de Salvador Pérez o la de Iohan Payz, no usan la fórmula en la que encontramos con regularidad muito ${ }^{25}$.

En definitiva, aunque en este apartado encontramos más variación que en los anteriores, vuelve a ponerse de manifiesto la continuidad del gallego. La no continuidad está motivada de nuevo por los usos de notarías ajenas a la zona y en algunos casos por la presencia de usos formularios ${ }^{26}$.

\subsubsection{Otros}

Hay algunos otros rasgos fonéticos que pueden resultar caracterizadores también para los que contamos con muy pocos datos. Es el caso del tratamiento dado a $\mathrm{G}^{\mathrm{e}, \mathrm{i}}$ - o a J-, en el que coinciden gallegoportugués y asturianoleonés / $3 /$ frente a la pérdida

23. Iohan Domínguez figura en un único documento en esta colección, el no 35, de 1274, en el que declara: "Yo, Iohan Domínguez la escriuí por mandado d'Esteuan notario público del rey en Uillafranca". En él aparecen ocho y ochobre junto a dito, dereyto, feyta y peyte. Para octubre encontramos en otros dos testimonios, octubre y ouchoure, pero ningún caso de vocalización de la implosiva.

24. En dos ocasiones consta eleyto, voz usada también en el castellano medieval, DCECH, s.v. elegir.

25. Recordamos que el diptongo oi en oito y noite, pero $u i$ en muito, resulta coincidente con la situación en las hablas del bloque oriental del territorio lingüístico gallego (Fernández Rei 2002: 328).

26. Insistimos en el carácter excepcional de ocho en la notaría de Iohan Domínguez. 
del castellano (Lleal 1990: 186). En solo dos ocasiones se menciona el mes de enero, las dos con la grafía ieneyro, es decir con la que corresponde a la pronunciación palatal sonora gallega y leonesa (Vázquez Diéguez 2018: 131; Morala 2004: 558); sin embargo, en las también escasas ocasiones en las que se hace referencia a hermano, -a no hallamos $g$ sino $h$.

Son pocas las palabras que contienen el grupo -MB- latino, palonbar, anbos, anuos o concanbia, que en ningún caso muestran la reducción $m$, rasgo en el que de nuevo vemos la continuidad del gallego en leonés, concretamente en Espinareda, frente al castellano (Lleal 1990: 186; Morala 2004: 558).

Son muy abundantes, en cambio, los ejemplos de mantenimiento de los diptongos decrecientes /ow/ / ej/ procedentes de AU o AL+ consonante y AJ (cousa, pouco, outorgamus, toucino, outros, leuou, mandou, plougo, pronguesse, meyrino, queyxumes, mandey, celleyro, escudeyro, etc., que conviven con abundantes casos de reducción ${ }^{27}$. Sucede lo mismo con la no diptongación de las vocales breves tónicas latinas, o al menos con su no representación gráfica, ponte, terras, Deus, sortes, solos, festa, pelle 'piel', mol 'muele', boys 'bueyes', etc., que alternan con formas diptongadas, tiampus, tierras, conuian, diez, fuero, ruego ${ }^{28}$, incluidas las del verbo ser ("ela nuestra yuguería del Outero de Langre que ya de la nuestra cozina»; "así como ye costumme») y de la conjunción copulativa («todo el outro herdamento que [...] comprey de García Fernández en Canedo ye en San Martyno»); es esta la forma más habitual que ofrecen los escritos del asturianoleonés occidental en el XIII (García Arias 1995: 626; Morala 2004: 557 y 560). Abundan así mismo los ejemplos de confusión de líquidas /1/ y /r/ que forman parte de un grupo consonántico: prugo, preyto, prazer, dobre, dubre, conprir, prazio 'plazo', brancos, mobre, etc., usuales en ambas variedades (García Arias 1995: 633; Morala 2004: 567) ${ }^{29}$.

\subsection{Análisis morfosintáctico}

Hemos seleccionado en este apartado dos fenómenos que no se dan en el corpus de Espinareda con carácter sistemático cuya presencia, sin embargo, nos parece significativa en la caracterización lingüística que buscamos.

27. Coincide la situación con la que describe Morala (2004: 557) para la documentación leonesa en el siglo XIII, es decir, estos diptongos decrecientes son más abundantes en el occidente, aunque aparecen también más ocasionalmente en el centro y oriente, en general coinciden en un mismo texto con formas monoptongadas y afectan a desinencias verbales, nombres propios, todo tipo de apelativos, pronombres y partículas.

28. Como suele suceder en la documentación del xiır del occidente de Asturias y León, es mucho más escasa la representación de diptongación de Ŏ que la de $\breve{E}$.

29. Dejamos para trabajos posteriores más extensos la descripción y el análisis de estos y otros rasgos. 


\subsubsection{Infinitivos conjugados}

Egido (2009: 24-25) caracteriza los infinitivos conjugados presentes en la documentación leonesa como formas de infinitivo con desinencias personales (-es, -mos, -des, -en), o sin ellas cuando se trata de la primera y tercera personas del singular, iguales a los infinitivos personales existentes en gallego y portugués, descritos, entre otras fuentes, en Ferreira \& Osorio (2008: 57) ${ }^{30}$. Hasta fechas relativamente recientes se consideraba que eran propios y exclusivos del gallego y portugués, pero Egido (2009: 24-28) ha recogido una buena muestra de su uso en testimonios occidentales medievales (Moreruela, Salamanca, Fuero de Ledesma y Coria), sobre todo leoneses (Sahagún, León, San Esteban de Nogales, Astorga y San Andrés de Espinareda). No hay constancia de estos infinitivos flexionados en el asturiano, esto es, al norte de la cordillera (Lorenzo González 2016: 56). Al sur, es precisamente en San Andrés de Espinareda, la localidad más occidental de las que analiza Egido, donde se hallan más testimonios de su empleo ${ }^{31}$ :

Hyou, don Steuano, pella gracia de Deus abbade de Sant Andrés d'Espinareda, con todo el conuento desse mismo lugar [...] damusuos e outorgamus ela nuestra yuguería del Outero de Langre que ya de la nuestra cozina [...] per tal pleito [...] que seerdes uasalos del abbade de Sant Andrés sem outro senorio [...] e fazerdes seruicio al abbade de Sant Andrés como a señor. E por estos foros sobredictos desta carta seerdes quitos de manio e de nuncio (Doc. 17, 1256. Martinus)

You, don Arias, pela gracia de Deus abbat de Sant Andrés, conno conuento desse mismo lugar, a uos, Iohan Rodríguez [...] damosuos um poulo e um orto que auemos en Uilafranca [...] per tal pleito: que los tengades de nos por en uossa uida [...] e laurardes ben e sin engano este maiolo e este orto [...] e dardes cada ano desde este sam Martino primero que uen a VI annos $\mathrm{V}$ soldos a quen quier que tenga el nosso uestiario. $\mathrm{E}$ a uosso finamento de uos todos tres leyxardes nos este maiolo e este orto sobreditos (Doc. 22, 1266. Martinus)

Yo, don Areas, arçediagano d'Astorga, uendo a uos, Menén González, e a uossa muller,

30. Señalan estos autores, a propósito del plano morfosintáctico, una "idiossincrasia destes dois idiomas do Noroeste peninsular ibérico que, entre as demais línguas románicas e até indo-europeias, só está documentado para dialectos napolitanos do séc. XV, e para o leonês medieval, o infinitivo com flexôes pessoais". El paradigma que presentan para su uso en gallego, portugués y mirandés es el siguiente: eu dar-Ø, tu dar-es, ele dar-Ø, nós dar-mos, vós dar-des, eles dar-en.

31. Recogemos a continuación los casos que encontramos en el corpus que manejamos. Egido (2009: 27 y 28) aporta estos y otros ejemplos de Espinareda que llegan hasta 1387. Como los fragmentos van más allá de la mención aislada de la forma verbal, que sin contexto resultaría difícil de interpretar, señalamos los casos de cada documento e indicamos al final el número del mismo en la colección, la fecha de emisión y el notario correspondiente; seguimos el mismo procedimiento en el estudio léxico. En la transcripción, salvo error involuntario, respetamos la que se hace en la edición citada, incluida la acentuación, puesto que, como ya hemos señalado, no hemos tenido aún acceso a los originales. 
Eluira Pérez, toda quanta heredade yo conprey en Canedo de María Fernández [...] E outorgo quella ayades por iur d'erdade para uender e donar e enguayar e para fazerdes della toda uossa uolontade (Doc. 42, 1280. Gonzalo Rodríguez)

Nos, don Arias, pela gracia de Deus abbade de Sanct Andrés d'Espinareda, e el conuento desse mismo lugar damos a uos, Pedro Pérez, e a uossa muller, Marina Pérez, un nosso poulo conas uides questan encima dele [...] per tal preyto: que chantedes este poulo iadito de uinna e que seia ben pourado dela ata cabo de oyto anos primeyros que uenen, e tenerdes lo todo por en toda uossa uida de anbos e dous, e dardes cada ano a nos e al nosso monesteyro iadito por elo en foro III canados de uino da qualque Deus hy der a la dorna. (Doc. 49, 1283. Martín Iohanes)

Todos estos heredamentos sobreditos así como aquí son determinados [...] outorgamos per tal pleito: que los tengades de nos en préstamos por en todos uossos días [...] E qual de uos quier que ficar pus finamento del outro tener estos heredamentos por en sos días, e a uosso finamento de anuos leyxardes nos estos heredamentos sobreditos liures e quitos con todos los outros que sacardes por nostro nomre (Doc. 55, 1286. Martín Iohanes)

Nós, abbat e conuento sobreditos, por este algo e por esta elmosna [...] outorgamos e prometemos de fazer cada anno conplido aniuersario por alma de Menén González, e despoys que uos finardes de lo fazermos por uos e por el assi commo ye costume del nuestro monesterio [...] Et prometemos e outorgamos de uos aiudar e uos anparar a uos e a todas las uuestras cousas [...] E non uenderdes nen allenerdes nen sopenorardes nenguna cosa destos heredamentos sobreditos, mays tenerdelos en bon paramento en toda uuestra uida e a uuestro finamento leyxardeslos liures e quitos al monesterio sobredito [...] se lo assí non feziermos, que uos peytemos en pena mil marauedís de la moneda noua, e a todas guisas el preyto remanecer firme (Doc. 65, 1289. Domingo García)

Yo, Pero Gil, e mia moller, María Pérez, vendemos a uos, don Gonzalo Ceruera, [...] duas casas con suas curradas [...] E obrigamos a nos, a todos nuestros bennes, de uos $f a-$ çermos de paz esta vençion sobredita de quenquier que uolla demandar (Doc. 68, 1291. Alfonso Eanes)

Estas formas conjugadas de infinitivo son conocidas en una gran parte del actual territorio lingüístico gallego; aunque ciertos hablantes en algunas zonas presentan solo una parte de las desinencias del paradigma, en otras áreas se recoge el paradigma completo. Es el caso, en general, de toda la costa gallega, sobre todo el oeste de Coruña, el centro-sur de Pontevedra, el oeste de Ourense y el sur, en la frontera con Portugal (García Gondar 1978: 153).

Como señala Egido (2009: 28) la preferencia de uso de la forma conjugada frente al infinitivo no parece depender de construcciones ni de reglas fijas, sino que posiblemente intervienen factores subjetivos o enfáticos, en definitiva, de la decisión e intencionalidad de quien redacta el documento. Los tipos de oraciones en los que se insertan son variados y sus valores diferentes. 


\subsubsection{Pronombre sujeto de primera persona singular: eu / you / yo}

Finalmente vamos a ver el reparto de las formas del pronombre personal, en la serie tónica, para la función de sujeto, pues el corpus de San Andrés de Espinareda da cabida a la forma gallega y portuguesa eu (Lleal 1990: 222), a la asturianoleonesa occidental you (Morala 2004: 557) y a la castellana yo. Veamos su presencia y distribución.

Puesto que en este caso la variación es más amplia, optamos por presentar los resultados en función del lugar en el que ejerce el notario. Dos documentos pertenecientes al mismo notario de Astorga usan yo, igual que uno de Villafranca. En los tres relacionados con un único notario de Ponferrada, se usa you en dos y eu en uno. En las notarías de Cacabelos se registran cinco documentos que usan solo eu, tres en los que alternan eu y you y siete en los que lo hacen eu y yo. Los notarios del monasterio usan solo you habitualmente (a veces con grafía hyou), en siete documentos, con la excepción de uno solo, Alfonso Eanes que, ya a finales de siglo, en 1291, recurre a $y o^{32}$.

La variación en este caso es más evidente: un mismo notario puede usar distintas formas en documentos diferentes y son varios los testimonios en los que alternan dos de ellas, como sucede en los relacionados con notarios de Cacabelos que muestran eu / yo o eu / you. No observamos en estos casos de alternancia un patrón en el cambio del pronombre. Por ejemplo, en el documento 24, fechado en 1270, leemos «eu, Martín Miguélez» en la intitulatio, uso que se repite en la dispositio; de nuevo aparece al inicio de la sanctio, pero poco más adelante en la misma sanctio, leemos, por este orden: «yo, Martín Mygaélez», «do yo a uos» y «eu, Martín Mygaélez»; los fiadores van todos precedidos de yo y el notario, Pedro Gonzáluez, de eu. La distribución de variantes se nos muestra igual de arbitraria aparentemente en las demás ocasiones. Quizá lo más significativo sea que entre los notarios de Cacabelos es usual $e u$, solo o en alternancia con yolyou, mientras que los notarios del monasterio no usan eu en ningún caso sino you, con una sola excepción, ya a finales del siglo de yo. A tenor de lo visto en otros rasgos, podría llamar la atención que aquí no haya ni siquiera alternancia entre la forma gallega y la leonesa, sino que se use esta última y es que, en definitiva, en la descripción lingüística de ciertas áreas norteñas peninsulares no podemos esperar sistematicidad y menos aún un uso regular de variantes que hoy atribuimos por separado a una u otra variedad de dos en contacto.

\subsection{Análisis léxico}

32. Quedan al margen dos documentos de Martinus, para el que no tenemos referencia, que usa you en dos y un tercero, que vuelve a usar yo, junto con un ego. Otro de Fernandus, también sin referencia, que usa eu; y dos más sin notario, uno con you y otro con $e u$. 
Los lemas que hemos seleccionado y que mostramos a continuación, organizados en tres grandes grupos por criterios onomasiológicos, junto a un apartado final sobre la no consideración de occidentalismos fonéticos, resultan frecuentes en el conjunto de textos denominados "galaico-leoneses» y habituales en las escrituras forales, de venta, donación e intercambio de bienes del siglo XIII, en este particular espacio geográfico de transición entre distintas variedades lingüísticas ${ }^{33}$.

\subsubsection{Léxico de la descripción del espacio}

Dentro de los términos que nominan posesiones rústicas, poulo ${ }^{34}$ se refiere al 'terreno de monte que se destina al cultivo momentáneamente':

[...] You, don Arias [...] conno convento [...] a vos Iohan Rodríguez e a uossa muler [...] e a uosso filo. damos uos un poulo e un orto que auemos en Uilafranca. El poulo iaz hu chaman Bergonno [...] que chantedes este poulo sobredito todo de uinna e que seia ben chantado e ben enuinado todo (Doc. 22, 1266 Martinus notuit)

[...] Damos a vos Pedro Pérez e a vossa muller Marina Pérez hun nosso poulo conas vides que estan encima del que fezo hy poner vossa sogra (Doc. 49, 1283, Martin Iohanez)

Derivado del latín PABǓLUM, 'pasto, alimento', aparece cuatro veces en el documento en el que el abad de San Andrés de Espinareda dona unas tierras a Juan Rodríguez. El sintagma goza de una veterana antigüedad, pues se encuentra también en los documentos del Tumbo Viejo (Pensado 1983: 70), en el Tumbo de las viñas reales de Ribadavia del archivo de la Catedral de Ourense (Méndez 2016: 262), y en la documentación de la catedral de León y del monasterio de Carrizo ( $C D H$ ). La voz pervive hoy en día tanto en El Bierzo (Krüger 1947: 132; García de Rey

33. Para el estudio de las voces que presentamos a continuación, además de las obras lexicográficas del castellano y del leonés, utilizamos los recursos elaborados en el Instituto da Lingua Galega de la Universidad de Santiago de Compostela, el Tesouro Medieval Informatizado da Lingua Galega (TMILG), Tesouro informatizado da Lingua Galega (TILG), Tesouro do léxico Patrimonial Galego e Portugués (TLPGP), el Dicionario de dicionarios do galego medieval (DdD) que contiene todos los glosarios medievales del gallego junto con el Dicionario da Real Academia Galega (DRAG). Para algunos términos nos hemos servido del Glosario da poesía medieval profana galego-portuguesa elaborado en el CCHS del CSIC, pues recoge el léxico galego-portugués de las cantigas trovadorescas profanas, el Dicionário Priberam da Lingua Portuguesa (DPLD) y por último, el Diccionariu de la Llingua Asturiana (DALLA).

34. El TLPGP (s.v. poula) la constata en las localidades de Navia de Suarna (Lugo), Porto (Zamora), A Mezquita, Gudińa, Vilardevós, Cualedro, Baltar, Lobeira y Montederramo (Ourense). Bajo el lema poulo en la provincia de Ourense, en concreto en Vilarińo de Conso y Ponteaereas. 
1934: s. v. poulo) como en portugués (DPLD) y en gallego con la forma femenina como predominante con tres acepciones, según Atlas Lingüistico Galego (mapas 4b, $6 \mathrm{~b}$ y $7 \mathrm{~b}$ ), 'monte con uces e toxos altos, bouza' en tres puntos de la provincia de Ourense (Baños de Molgas, Xinzo de Limia y Calvos), 'monte con árbores pequenas, ramalleira' en dos puntos del sur de Ourense (Cualedro y Oímbra) y en el norte de la provincia de A Coruña (Beba), por último, 'monte de vexetación baixa, graña' en Chímparra (Cedeira, A Coruña) y en Soutelo (Vilariño de Conso, Ourense). En los diccionarios gallegos poula aparece por primera vez en el Diccionario Galego-Castelán de Carré (1951) según el $D d D$.

Para el 'corral de cierta extensión cerrado' se recurre a corradalcurrada ${ }^{35}$ en dos documentos:

[...] Predictum uero solarem habet terminos per terminos meos et de illos Crezules et de filios de Iohanne Petriz et ortum est per terminos de Fernando Martiniz et sub illa corrada de los Crezules et subtus illa carrale antiqua. [...] Et unum pratum in illa corrada subtus carrera per terminos de Fredinando Uiola et de filios de Iohanne Petriz. (Doc. 4, 1170; no consta notario)

[...] Duas cassas con suas curradas e una terra que nos avemos eno Favero (Doc. 68, 1291, Alffonso Eanes)

Uno de los modos de apropiación del terreno comunal para el disfrute privado consistía en cercarlo haciendo una corrada. Derivado de corral, corrada ${ }^{36}$ se atestigua en registros asturianos $(D A L L A)$, gallegos (TILG) y leoneses (Le Men). En la actualidad se sigue usando según los repertorios léxicos del Bierzo Alto (Castro Antolín 1987), gallegos (DdD, TLPGP) y asturianos, tanto en la acepción de 'corral' como en la de 'mullido de pajas y zarzas situado delante de la casa para que se convierta en estiercol'.

El lema cortina alude en los documentos de Espinareda al 'terreno cercado de cultivo próximo a la casa':

[...] uendemos a uos García Pérez e a uuestra muller, María Pérez, una cortina con suos áruores e meatade de una casa con sou coral e con sou dereyto que iaz en Uilella, sub signo de Santa Marta (Doc. 35, 1274, Estevan notario)

Derivado de CŎRS o CŎHORS con el sufijo diminutivo -ina, se trata de una voz antigua, frecuente y con amplia difusión por los territorios del leonés y del gallego.

35. El TLPGP (s.v. corradalcurrada) atestigua el lema en las localidades de Tapia de Casariego (currada), A Fonsagrada, Castroverde y O Corgo (currada).

36. El TLPG documenta este lema (s.v. cortiña) en las localidades de Pedrafita do Cebreiro, A Fonsagrada, Ribadeo, O Valadouro, Vilalba, Pol, Guntín (Lugo), Ramirás, Vilariño de Conso, Montederramo, Castro Caldelas y Parada de Sil (Ourense) y en Aranga y Dumbría (A Coruña), en Vilaboa y Cangas (Pontevedra) y por último en Porto (Zamora). 
Desde el punto de vista semántico, su significado es parecido al actual cortinal, si bien, como afirma Álvarez Maurín (s.v. cortina), parece tratarse de una tierra de cultivo intensiva en las dependencias o cercanía de la corte (también Méndez s.v. cortina). De la lectura del fragmento se interpreta que es una superficie $\operatorname{acotada}^{37}$. En gallego actual se ha especializado para referirse en concreto al cultivo de legumbres y cereales (DRAG, s.v. cortiña). El Atlas Lingüistico Galego (mapa 4b) lo sitúa con la acepción de 'monte con uces e toxos altos, bouza' en A Terrachá, sur de Ourense en la frontera con Portugal.

Por su parte, el término yuguería nombra el 'espacio de tierra de labor que una yunta puede arar en un día':

[...] damusuos e outorgamus ela nostra yugueria del Outero de Langre que ya de la nuestra cozina, con todos sous dereytos quantos le pertenezen en monte e en villa, per tal pleyto que aiades uos [...] con toda uuestra generación que de uos uener que poblaren aquel lugar ela meatade desta yugueria (Doc. 17, 1256, Martinus notuit)

El vocablo aparece en un documento de la cancillería castellana dirigido al monasterio de Montederramo, conservado en el archivo de la catedral de Ourense $(D E D A \text {, s.v. })^{38}$, así como en los documentos romances de la zona sanabresa (en la documentación del Monasterio de San Martín de Castañeda) de El Bierzo y en los documentos de la catedral de León $(C D H)$. En documentos leoneses y en las ordenanzas de Ávila se utiliza en la acepción de 'impuesto o tributo’. En la actualidad se sigue utilizando en zonas de Asturias y León.

La laboría ${ }^{39}$ identifica la 'tierra dedicada al cultivo':

[...] a vosso finamento de uos todos tres leyxardes nos este maiolo e este orto sobreditos con todas suas lauorias e con suos chantados liures e quitos que nenguno non nos faga hy contraria. (Doc. 22, 1266, Martinus notuit)

Se trata de un sustantivo formado a partir de labor más el sufijo -ia, con la acepción tanto de 'parcela de tierra' como de 'tiempo que dura la labranza o siembra',

37. Varela Sieiro (2008: 258-263: s.v. cortina) tras el análisis de un centenar de documentos notariales gallegos afirma que las distintas grafías indican una posible pronunciación palatal del término.

38. Según Sánchez González de Herrero (2003: 445), «existen variantes lingüísticas relacionadas con la zona a la que van dirigidos, es decir, los documentos de la cancillería real emplean [...] voces propias de los lugares a los que se destinan; [...] en otros casos, nos hallamos ante voces propias de la zona, diatopismos que reflejan la forma usual de un determinado significado en un área más o menos amplia de la Península en la segunda mitad del siglo XIII».

39. El TLPGP sitúa la voz en las localidades de A Fonsagrada, Viveiro, Ribadeo y Mondońedo (Lugo); fuera de Galicia se utiliza también en zonas asturianas, salmantinas (Pérez Rodríguez 2011: 948) y en determinadas áreas de León para designar los trabajos del campo (Álvarez Maurín 1994: s.v. labores). 
según el DRAG y el TMILG.

Por su parte, molnera alude a una 'presa de molino':

[...] fago carta de uendición e de donación a uos, don Arias [...] de la meatad de las molneras que ey enno terreno de Ponfferrada, atana ponte de San Pedro (Doc. 19, 1264, Pedro Perez qui notuit)

[...] douuos e outorgouos para todo tenpo todo quanto ey, e deuo a auer, que me perteneze e deue a pertenezer enna uilla que chaman Salzedo [...] conuen a saber terras, uinnas, arbores prados pascos montes fontes entradas frontadas molineras exidos e divisos todo uolo dou e uolo outorgo por iuro de heredade (Doc. 29, 1272 Martin Iohanes, capellam del monesterio, escreuio esta carta)

Entre las dependencias del molino encontramos las molinarias, molneras o molinayras con distintas transformaciones y evoluciones del sufijo-aria. Se trata de un adjetivo derivado de molina, que aparece utilizado ya en la latinidad tardía como sustantivo. Se halla en documentos gallegos, leoneses (Varela Sieiro 2008: 333-336; Álvarez Maurín 1994: 294, $C D H)^{40}$ y cántabros medievales $(C D H)$.

Por último, para hacer referencia al 'asiento de un edificio', los escribas recurren al lema sessega:

[...] damos e outorgamos a uos, nosso criado [...] en ela nossa sessega que auemos en Ueyga, que foy de Ruy Pérez, assí como iaz con suas casas, e con sua bodega, e con sous corrales, e con sous solos, e con sous exidos, e con sua corrada, e con sous árbores, e con sou palonbar [...] que non cayan por vossa encuria, e que nos diedes cada anno desta sessega en renda I moravedí por la festa de San Iohan Baptista [...] E nos que lo tengamos de vos por en todos nossos días con esta outra sessega, e a nosso finamento de ambos que vos fique libre e quito (Doc. 25, 1270, Fernadus notauit)

Se trata de un deverbal del latín hispánico *SESSECARE 'asentar' (DCECH, s.v. sosegar) que encontramos por primera vez en un documento de 759 de la diplomática asturleonesa (Álvarez Maurín 1994: 186-187) y que aparece muy frecuentemente en documentos gallegos del siglo XI, ya que su uso está relacionado con el estilo de redacción notarial, en el que abundan las enumeraciones formulares (Varela Sieiro 2008: s.v. sesicas; sesigas y sesicias). El DCECH confirma su presencia en gallego antiguo, donde se utiliza en masculino (en documentos del Monasterio de San Clodio do Riveiro y en los de Viveiro en la Edad Media) y en femenino (en el Tumbo de las viñas reales de Ribadavia del archivo de la Catedral de Ourense, Méndez 2016: s.v. sésega). Mientras que en los documentos gallegos ${ }^{41}$ (Varela Sieiro

40. El $C D H$ contiene siete apariciones de molnera para los siglos XIII y xIV que se localizan en documentación de León (2), Santander (4) y en una carta real alfonsí dirigida a Galicia.

41. «Aparece siempre junto a molino con lo que piensa que se refiere a un emplazamiento que reúne 
2008) y leoneses (Álvarez Maurín 1994: 186-187) el término se utiliza en su acepción especializada de 'lugar destinado para la edificación, particularmente de un molino', en nuestros documentos se emplea en su acepción más general, que coincide con la portuguesa ${ }^{42}$. En la actualidad la voz pervive en gallego, sésega, con dos acepciones 'fenda, concavidade ou rebaixe que hai ou se fai nunha cousa para encaixar outra' y 'sinal que unha corda, goma etc., moi apertada deixa na parte do corpo ligada' (DRAG) y en asturiano siésiga con la acepción de 'piedra [onde s'asitia un caxellu]' (DALLA)

\subsubsection{Léxico de la vida cotidiana}

En este apartado se incluyen voces relacionados con aspectos muy distintos de actividades habituales que en la lexicografía histórica suelen agruparse bajo esta etiqueta.

En lo que se refiere a los alimentos y a los productos derivados de ellos, la voz regaifa ${ }^{43}$ se usa para designar una 'torta':

[...] darnos cada ano en renda VI modios de centeno per bona emina del melor pan desta heredade por sancta María de agosto, et pola festa de sant Andrés XII sólidos de dineros, et VI eminas de ceuada per bona, e VI galinas e VI regueyfas, todas feytas de una emina pela bona de trigo et dar VI sólidos al abbade de Sant Andrés por iantar cada ano (Doc 11, 1256, Martinus)

Se trata de un arabismo, del ár. ragâaif, plural de ragîifa (DCECH, s.v. regaifa y Corriente 2008: s.v. regaifa 'cake'), que se refiere a una pieza de pan u hogaza. Este documento proporciona una de las primeras documentaciones del lema, que goza de plena vigencia en textos notariales gallegos del siglo xIv (TMILG). La forma medieval regueifa se corresponde con la del gallego actual en las acepciones de 'molete de pan adornado con ovo, azucre, caramelo etc., con que se obsequia aos invitados a unha voda e aos veciños dos noivos'; 'disputa dialéctica improvisada e en verso, especialmente entre os asistentes a unha voda' y por último, 'roscón que gañaba a parte que mellor facía a regueifa [='improvisación poética popular'] nunha voda' $(D R A G)$. En la actualidad se utiliza también, en su acepción etimológica, en asturiano (DALLA) y portugués (DPLD).

las condiciones necesarias para la edificación de un molino o a un lugar donde existen molinos ya construidos» (Varela Sieiro 2008).

42. 'Assento ou terrado não só de qualquer edifício mas tambem das árvores' (Santa Rosa de Vitervo 1865: s.v. sesega)

43. El TLPGP (s.v. regueifa) confirma la presencia del lema en las localidades de Curtis y Dumbría (A Coruña) y en Campo Lameiro en la provincia de Pontevedra. 
Con los lemas serandalla ${ }^{44}$, ervanço y ervella, los documentos se refieren al 'grano o fruto tardío' como los 'garbanzos' o los 'guisantes' respectivamente:

[...] E esto uos dou por aiuda del uosso uestiero porque sey que la auedes mester, e todos elos outros diezmos retengo para nos e para nossa mesa e de los outros abbades que despoys dnos uenieren, conuien a saber diezmo de lino e de sirgo e de ganados e de bestias e de toda serandalla assi como fauas e eruellas e eruanços legume e fructas. (Doc. 33, 1274; no consta escribano)

Serandalla procede del lat. SERŌTǏNUS 'tardío' y del adverbio SĒRŌ 'tarde' ( $D C E C H$, s.v. serondo). Este diccionario recoge la definición de un vocabulario del siglo XV «serondajas deçimos por los garvanzos y havas, arvejas y otras legumbres que se siembran tarde», que coincide con la acepción en este documento. Es voz frecuente en los textos occidentales, con múltiples variantes, como las que aparecen en el Tumbo Viejo de San Pedro de Montes ${ }^{45}$. Entre las formas gallegas actuales encontramos el sustantivo serodio (que alude tanto al centeno como al maíz tardío, o a un castaño alto) y el adjetivo sorodio ('verde, tardío') (DRAG).

La voz arveja, 'guisante', uno de los hipónimos de serandalla, cuenta con distintas variantes fonéticas. El DCECH, s.v. recoge arveilla en Sanabria, arbeyu en Asturias, herbella en Galicia y ervilha como nombre del 'guisante' en casi todo Portugal; el TLPGP documenta la variante arvellaca.

Paralelamente, y con respecto al hipónimo ervanço, el DCECH, s.v. garbanzo, afirma que «en gallego-portugués se encuentra garvança en las Cantigas de Santa María (IX, 14), pero ervanço en Mestre Giraldo (a. 1318) [...]; hoy se dice garabanzo en gallego (Sarm., CaG. 91v; Vall.), donde quizá haya existido también herbanzo».

Como 'medida de capacidad para líquidos' se menciona el canado ${ }^{46}$ :

[...] dardes cada ano a nos e al nosso monesteyro ia dito por elo en foro III canados de uino da qualque Deus hy der a la dorna. (Doc. 49, 1283, Martín Iohanes)

Según el $D C E C H$, s. v. cañada, el origen de la voz es un derivado del lat. CANNA,

44. El TLPGP (s.v. serodio) la confirma en las localidades de Laxe, Cee, Aranga, Melide y Touro (A Coruńa), Guitiriz, Guntín, O Corgo, Castroverde, Sarria, A Fonsagrada y Pedrafita do Cebreiro (Lugo), Silleda, A Estrada, Campo Lameiro, Ponteareas, Tomińo (Pontevedra), Castro Caldelas, Montederramo, A Mezquita, Villardevós y A Gudiña (Ourense).

45. Por ejemplo serodano, serodono, serondao con resultados cercanos a la solución gallega y portuguesa (Pensado 1983: 73-74).

46. El TLPGP (s.v. canada) constata esta voz en las localidades de Valadouro, Guntín, Monterroso, Sarria, O Corgo, Castroverde, Pedrafita do Cebreiro, A Fonsagrada (Lugo), Silleda y A Estrada (Pontevedra), Laxe, Dumbría, Cee, Carballo, Ames, Negreira y Porto do Son (A Coruña) y Ramirás (Ourense). 
'caño por el cual sale el líquido de la cañada'; por lo tanto indicaría 'un recipiente o medida para el agua'. Morfológicamente, el sintagma puede ser masculino o femenino tanto en la variedad gallega (TLPGP s.v. canado y canada, Varela Sieiro 2003: s.v. canado) como en la leonesa (Le Men s.v. cañada). Se trata de una medida con equivalencia variable tal y como sucede con muchas de las medidas de la época medieval, si bien Varela Sieiro (2003: 283) establece una equivalencia precisa en documentación medieval gallega ${ }^{47}$.

Entre los numerales se recoge trinta $^{48}$, del latín*TRIGINTA, o bien *TREGINTA, variante bien documentada en gallego y portugués $(D C E C H$, s.v. tres, $D P L D, D d D$, TMILG y $T I L G)$ :

[...] saluo ende ela casa con sou lagar que está cabo ela ponte que fique al obedencial de la cozina en que faga sou vino. Todo esto uos damos e outorgamos per tal pleyto [...] que adubedes ben ela bodega hu mester for, e que tengades en ela al obedencial de la cozina cada ano trinta modios de uinno de sou en suas cubas (Doc. 25, 1270, Fernadus notuit)

La dorna ${ }^{49}$ identifica la 'cuba o tina para pisar la uva':

[...] e dardes cada ano a nos e al nosso monesteyro iadito por elo en foro III canados de uino da qualque Deus hy der a la dorna. (Doc. 49, 1283, Martín Iohanes)

Dorna, 'cuba para pisar la uva', en gallego y portugués, duerna, 'artesa', en castellano antiguo y asturiano, es voz de origen incierto, coincidente con el occitano dọrn, francés antiguo dour, francés dialectal dorne, 'medida de longitud', cuyo significado pudo extenderse a una medida de capacidad y luego a la vasija empleada para medirla, posiblemente relacionada con un céltico DÜRNO- $(D C E C H$, s.v. duerna). Se trata de un sintagma frecuente en el antiguo reino de León (Le Men) y en Castilla para designar utensilios variados para distintos fines; morfológicamente varía entre el masculino y el femenino. Respecto al significado, Sieiro Valera (2003: 294) sostiene que en asturiano mantiene la acepción de 'artesa', que es la que recoge básicamente el $D A L L A$, s.v. duerna, donde se define como 'recipiente' para el que

47. «E quizais para cońecer a súa dimensión teñamos que valorar asermade eses 32 litros que aínda hoxe leva un canado e que posiblemente nalgún momento sería empregado tamén como unidade de medida».

48. El TLPGP (s.v. trinta) la localiza en las localidades de Cangas (Pontevedra), Xermade, Vilalba, Abadín, Cospeito (Lugo) y Villanueva de Oscos (Asturias).

49. El TLPGP (s.v. dorna) recoge esta voz en las localidades de Porto do Son, Boiro, Rianxo (A Coruña), Vilagarcía de Arousa, O Grove, Marín, Cangas, Redondela, Baiona (Pontevedra) y Riós (Ourense). Todos los lugares citados son puertos de mar, donde la denominación dorna es una forma viva que alude a una embarcación para la pesca característica de las Rías Baixas. 
se detallan distintos usos. Tanto en portugués (DPLD) como en gallego (DRAG) se usa en la acepción de 'cuba ou tina para pisar a uva', y 'recipiente que recibe el vino después de pisar las uvas'. En gallego actual se utiliza para aludir a 'pequena embarcación para a pesca de baixura’ (DRAG y Fernández Rei, Ínsua López \& Rei 2005: 15-17).

También queyxume ${ }^{50}$, 'queja, motivo de quejarse', o la misma quejumbre, se considera voz leonesa o de influjo occidental, muy viva en gallego y portugués, según el DCECH, s.v. quejar,

[...] sobre contenda que yera [...] por razon de queyxumes que el abbat e conuento sobreditos auíen de Fernán García sobredito de malfetrias que dezíen que fezieran él e suas conpannas ennos uassallos e enos clérigos e ennos caseyros e en outras cousas del monesterio sobredito (Doc. 71, 1294, Domingo García)

La palabra puede proceder, según el $D C E C H$, del gallego-portugués, introducida por influjo de la poesía amorosa y, como tal, la encontramos ampliamente documentada tanto en GLOSA como en TMILG a partir del siglo XIII.

Dentro del ámbito de los oficios y cargos, la voz clerizón designa al 'aprendiz de clérigo':

[...] E los que furon presentes [...] Pedro Goneyru conff<irma>. Martín Domínguez, clerizón, conff<irma>. Iohan Áluari conff<irma> (Doc. 19, 1264, Pedro Pérez)

Derivado denominal del lat. CLERICUS más el sufijo -zón, en castellano se usa con un matiz despectivo ( $D C E C H$, s.v. clero); lo encontramos ampliamente documentado en el Glosario da poesía medieval así como en el TMILG y en los diccionarios del gallego en el sentido de 'aprendiente'.

50. El TLPGP (s.v. queixume) localiza la palabra en la localidad de Campo Lameiro en Pontevedra. 
Otro de los oficios que recogen los documentos de Espinareda es el del vestiareyro:

[...] Miguel García, prior, confirma. Fernán Gonzáluez, monge, confirma [...] Todo el conuiento confirma. Pedro Pérez, uestiareyro t<estigo >. Iohan de Santa María, mayordomo, t<estigo> [...] (Doc. 22, 1266, Martinus notuit)

Esta palabra, además de referirse al oficio, tiene una segunda acepción como 'conjunto de piezas de vestir'. Es habitual en los documentos notariales gallegos según se recoge en el TMILG y en el DRAG (s.v. vestiario).

Entre las obligaciones que contiene el acuerdo que establece el abad del monasterio con Domingo Pelaiz y su familia, por la cesión de algunos bienes inmuebles, se incluye la de derrangar o derrancar ${ }^{51}$, 'arrancar o desarraigar' un monte:

[...] damos a uos [...] duas sortes que auemos enno Castro de Uentosa [...] Ambas estas sortes uos damos per tal pleyto que nos derranquedes un monte que auemos en essa uilla ia dita e iaz hu chaman Carral de Castro, e nos chantedes toda essa tierra de uinna, e la enuinedes ben toda (Doc. 21, no consta ni fecha ni notario)

Según el DCECH, s.v. arrancar, tanto el castellano arrancar como el gallego antiguo derrancar y el catalán arrencar, son de origen incierto; plantea que quizá su significado primitivo fue 'desbandar, vencer', en cuyo caso podrían derivar del catalán antiguo renc, o del francés antiguo ranc, 'hilera de tropa', procedentes del germánico HRING, que pasaría del sentido de 'romper las hileras' a 'desbandar', 'separar' y finalmente 'desarraigar'.

La documentación gallega lo atestigua desde antiguo, se halla en la Crónica Troiana (DCECH, s.v. arrancar) y aparece codificado por primera vez en el Diccionario Gallego de Juan Cuveiro Piñol (1876) según el $D d D$.

\subsubsection{Léxico jurídico}

Se suele insistir en el carácter estático, arcaizante y reiterativo de la lengua notarial, basada en la tradición, especialmente en lo referente al léxico jurídico y al uso de fórmulas que se repiten en las distintas partes del documento notarial, mediante palabras, giros sintácticos y fórmulas lingüísticas heredadas (entre otros muchos, Díez de Revenga 2001: 107). No es por tanto este un campo en el que abunden los diatopismos, aunque podemos señalar dos en los testimonios de Espinareda.

51. El TLPGP (s.v. derrancar) ubica la voz en las localidades de Touro (A Coruña) y Silleda (Pontevedra). 
El primero de ellos es britar, 'apoderarse de algo por la fuerza o ilegalmente', 'ir en contra de algo, incumplirlo o infringirlo', usual en las cláusulas de la sanctio de estos testimonios, sobre todo en el binomio passar ou britar ${ }^{2}$ :

[...] Et quen esta carta queser britar al otra parte péchele $\mathrm{C}$ morabetinos, e al rey peche CC morabetinos en couto (Doc. 17, 1256, Martinus)

[...] E qual de las partes a loutra parte esta carta britare peche $\mathrm{L}^{\text {a }}$ soldos a essa parte que recibir el [t]orto e la carta sea firme (Doc. 22, 1266, Martinus notuit)

[...] Et qual de las partes al outra parte esta carta passar ou britar peyte $\mathrm{L}^{a}$ marauedís a essa parte que recebir el torto, e al rey peyte $C$ marauedís en couto [Doc. 25, 1270)

[...] E qual delas partes a loutra parte esta carta passar ou britar, peche cem marauedís a essa parte que recebir el torto (Doc. 50, 1284, abril 12 Martin Iohannes)

[...] Se algum omme de nossa parte ou dextrana, a uos ou a uossa parte esta carta desta uentión passar ou britar, dobleuos esta heredat sobredita (Doc. 61, 1287, Martin Iohanes)

[...] E se algún ome della nuestra parte, ou della estrannia, a uos, ou a uossa parte, esta carta quisser passar ou britar dobleuos esta vençión sobredita en mellor lugar, e peyteuos por pena C marauedís (Doc. 68, 1291, Alffonso Eanes)

En la documentación notarial gallega existe abundante evidencia de la frecuencia de su uso desde 1240 y se sigue utilizando en la actualidad tanto en gallego como en portugués ${ }^{53}$ (DPLD y DRAG). Asimismo se encuentra en la Colección Diplomática del Monasterio de Carrizo ( $C D H$ ). El lema aparece por primera vez en la lexicografía gallega en 1884 en el Diccionario gallego castellano de Marcial Valladares Núnez, según el $D d D$.

En otro de los enunciados formulísticos habituales en la corroboratio de los testimonios notariales, concretamente en la serie en la que se enumeran las posibles acciones que un nuevo propietario puede ejercer libremente sobre los bienes que posee, se halla la posibilidad de empeñar o dar algo en prenda, expresada aquí mediante enguayar o engaiar:

[...] uendemos a uos [..] una cortina con suos áruores e meatade de una casa [...] Et outorgamos que lo aiades des aquí adelantre por jur de heredade para uender e para donar e para engaiar e para faser del todo uuestra uolontade, a uida e a norte (Doc. 35, 1274, Estevan notario)

52. Es muy amplia la bibliografía sobre el empleo en los documentos notariales de estos pares de sinónimos o parasinónimos cuya principal finalidad es la claridad y transparencia significativa (Lagüens 1992: 1122), al margen de la tendencia de la lengua medieval a la reiteración de un mismo significado mediante el empleo de dos o más significantes (Saralegui \& Pérez-Salazar 1992: 126).

53. Además, britar está presente en documentos alfonsíes dirigidos al reino de León (Sánchez González de Herrero 2005: 57). 
[...] uendo a uos [...] toda quanta heredade yo conprey en Canedo [...] E outorgo quella ayades por iur de erdade para uender e donar e enguayar e para façerdes della toda uossa uolontade a uida e a morte (Doc. 42, 1280, Fernán González)

El significado del vocablo es claro en ambos fragmentos ya que presentan un tipo de enumeración que se repite constantemente en las cartas de venta y de cambio de la Baja Edad Media peninsular. Carrasco (1987: 467) documenta engayar, agayar, 'empeñar, dar en prenda', en el Fuero de Zamora ${ }^{54}$; señala que no encuentra estas formas en fuentes lexicográficas y considera que puede tratarse de un derivado del galicismo gaje, 'prenda'. Engaiar consta dos veces, en fórmula idéntica, en un documento ${ }^{55}$ de 1160 de la Colección diplomática de San Salvador del Moral, la zona más occidental de Palencia (Serrano 1906: 67).

\subsubsection{Occidentalismos fonéticos}

Si consideramos las palabras teniendo en cuenta su evolución fonética acorde al occidente peninsular, podríamos presentar aquí una larga lista; no es esa la intención de este breve apartado sino, más bien ofrecer una pequeña muestra del tipo de voces que hemos dejado al margen en este trabajo ${ }^{56}$.

Contamos con la presencia de un arabismo azeymila, del ar. and. azzám(i)la y éste del ar. cl. zämilah (Corriente s.v. acémila), con el diptongo decreciente ei, típico de las variedades occidentales peninsulares, que aparece con el mismo sentido que en castellano, el etimológico, de 'bestia de carga':

[...] Otrossi dizían los priuilegios que non tomassen portagen en Uillafranca de sos uasallos del monesterio de nenguna cousa. Otrossi dizian que suas azeymilas que non fussen detenudas por deueda nen por outra cousa. (Doc. 27, 1270, Saluador Pérez)

54. «E non aya poder delo uender [el auer] ne delo engayar nen delo malmeter», fragmento procedente de los manuscritos Q y S que edita y estudia. Ańade que hay otro ejemplo de engayar en $S$ "escrito por el corrector según los editores (F. leoneses, p. 17 n. 6)”. En Carrasco \& Carrasco (1997, I, 587) recogen tres fragmentos más de engayar, agayar en los dos manuscritos del Fuero de Zamora sin que se atestigüen en los otros fueros leoneses que contemplan (Salamanca, Ledesma y Alba de Tormes).

55. Se trata de una donación mutua que de sus bienes hacen dos esposos, Pedro Rey y Sancha, en la que se puede leer: «de quantum nos habemus de hereditate et de aver [...] que faciatis inde quodqumque volueritis in diebus vestris, de vender, et de dar, et de engaiar, et post diebus vestris sit datum pro anima mea».

56. En 3.3.2. hemos comentado algunas voces como ervella o queyxume en las que el componente fonético es significativo, pero también lo es el criterio de su adscripción geográfica. 
En gallego, acimilero ${ }^{57}$ es 'persoa que transporta mercadorías con mulas (cast. acemilero)' (TLPGP).

Con otro diptongo decreciente occidental, en este caso ou, hallamos toucino ${ }^{58}$, que el $D C E C H$, s.v. tocino, considera voz peculiar del castellano y portugués, toucinho, procedente de *TŬCCINUM (LARDUM), derivado posiblemente formado ya en el latín vulgar hispánico. El sintagma se encuentra en leonés ${ }^{59}$ y en gallego con múltiples variantes dependiendo de la zona (touciño, tousiño, toucín):

[...] outorgamos a uos, donna Steuanina, por en toda uossa uida, de uos dar cada anno III moyos de pan per bona emina pola festa de santa María de agosto; conuen a saber, I moyo de trigo e II ${ }^{\text {os }}$ moyos de centeno, e II $^{\text {os }}$ medios de vino, a la dom por San Miguel, e I toucino pola festa de sant Andres (Doc. 29, 1272, [Mar] tín Iohanes)

También está presente aparellamiento ${ }^{60}$ con la misma acepción, tanto en gallego como en castellano, 'conjunto de objetos necesarios para una actividad':

[...] eu, Martín Miguélez, clérigo de Canedo [...] fago carta de uendizón a uos, don Menén Pérez [...] de todo herdamiento, pouco e muito, quanto eu ayo ena uilla que dizen Canedo [...] e con un lagar feyto con todo sou aparellamiento (Doc. 24, 1270 Pedro Gonzáluez)

Aunque este deverbal es frecuente en la documentación gallega a partir del siglo xv la lexicografía no lo codifica hasta finales del xviII.

En el aspecto léxico y en lo que respecta al uso de las voces propias del noroeste occidental, tres notarios destacan: Martinus, que mostraba preferencias lingüísticas más regulares respecto a determinados fenómenos fonéticos, utiliza seis términos en dos documentos: poulo (1266), yuguería (1256), laborías (1266), regueifa (1256), britar (1256) y vestiareiro (1266). Martín Iohanes, «notario público del abbat de Sant Andrés enos coutos», en seis testimonios que van de 1272 a 1287, se sirve en tres documentos distintos las voces poulo, toucino, canados, dorna, molneras y britar. Fernandus, del que no hay referencia del lugar de ejercicio, emplea en un mismo documento de 1270 britar, trinta y sessega. Estevan hace lo mismo en un documento de venta de 1274 con los lemas engaiar y cortina. Los notarios, a continuación, emplean una única voz: Pedro Pérez, "públicu notario del conzelo de Ponfferrada", usa el término clerizón en un documento de 1264. Fernan Gonzalvez hace lo mismo

57. El TLPGP (s.v. acimilero) la localiza en la provincia de Lugo, en concreto, en Vilalba.

58. El TLPGP (s.v. touciño) la recoge en distintas localidades de todas las provincias de Galicia.

59. Véase Le Men, s.v. tocino, para la distribución geográfica de las variantes (tocín, toucín, touciño, toucino, tucino, toucio, toucinho y tornino) en leonés.

60. El TLPGP (s.v. aparellarse) la ubica en la localidad de Pedrafita do Cebreiro en Lugo. 
con engayar en un documento de 1280, Salvador Pérez emplea azeymila en otro del 1270, Pero Gonzalvez «público notario de Cacauellos» utiliza aparellamiento en otro de 1270, Alffonso Eanes hace uso de britar y currada en un documento de 1291 y por último, Domingo Garcia "publico notario en Cacauellos» se sirve de queyxumes en un pleito de 1294.

En definitiva los documentos estudiados incluyen voces particulares y propias de la diatopía del noroeste occidental, en concreto comunes al gallego y al leonés durante la época medieval. Cabría destacar que pertenecen a campos muy distintos y algunas se siguen utilizando en la actualidad. Una parte de estas voces o de sus acepciones son peculiares por su uso restringido a esta zona lingüística de transición en el continuo dialectal peninsular norteño.

\section{Conclusiones}

En este trabajo no hemos pretendido describir la «variedad» lingüística que nos ofrecen los documentos de San Andrés de Espinareda; para alcanzar tal objetivo habría sido necesario, en primer lugar, el análisis de otros rasgos; pero, además, no ha sido esa nuestra intención, centrada más bien en describir la disposición espacial de ciertos hechos lingüísticos.

Hemos observado así que el resultado gallego de -LY- > / $/$ / llega en el siglo XIII hasta Espinareda y posiblemente su frontera, con área de transición, se situara un poco al oriente, pues los testimonios procedentes de las notarías de Bembibre y de Astorga ofrecen grafía y. Una situación análoga se observa en la evolución de PL-, KLy FL- $>/ \mathfrak{t} /$. Para -KT- y -(u)LT- latinos, la coincidencia con el gallego es mayoritaria pero no exclusiva, lo que nos permite sospechar que el área de transición en este caso concreto tendría comienzo algo más al occidente que en los rasgos anteriores. En distinta medida, las dos variantes morfosintácticas seleccionadas apoyan esta continuidad. Hemos buscado analizar la extensión particular de cada uno de los fenómenos estudiados por el territorio occidental de León, sin dividirlo en segmentos o en subáreas ${ }^{61}$.

En el léxico, las palabras seleccionadas muestran asimismo áreas geográficas de uso con extensión diferente, en la medida en que hemos podido comprobarlas, pero en todos los casos se ponen de manifiesto la continuidad y la suave transición lingüística. Hay que tener en cuenta que son escasos los estudios léxicos que se han

61. García \& García (1997: 18) afirma que la documentación del monasterio de San Andrés de Espinareda en la época medieval «constituye el ejemplo más claro de esa lengua fronteriza híbrida de ambos sistemas. Como es natural, se castellaniza muy pronto y sólo persisten rasgos vacilantes en la toponimia». Con relación a la toponimia, recoge tanto formas que considera asturianoleonesas (Chano, Rubiales, Asniquiella, Los Palombares, El Cotariello, etc.) como gallegas (Campelín, La Lama, Las Valias) e híbridas (Cubielo, Valados y Vallados). 
hecho hasta el momento sobre "documentos galaico-leoneses», carencia que no posibilita en ocasiones una mayor precisión, pero aun así contamos con testimonios claros de la existencia de diatopismos comunes a ambas variedades.

Una última consideración: en los trabajos lingüísticos basados en documentación bajomedieval es imprescindible tener en cuenta a los distintos notarios y su ámbito de formación, que pueden resultar claves en la interpretación. Hemos visto que, sin ser absolutamente regulares en los usos gráfico-fonéticos, como es esperable en la época bajomedieval, los notarios de Cacabelos y del propio monasterio coinciden de forma mayoritaria con los usos más occidentales; por ello, sorprende que en los testimonios de los notarios del monasterio precisamente no se utilice eu sino you / yo, para el pronombre sujeto de primera persona. Las soluciones más leonesas, del tipo conceyo, conseyo, xamado(s) o axaren, pertenecen a notarías más orientales, de Bembibre y Astorga en concreto. Los usos léxicos por notarios no pueden valorarse de manera paralela, puesto que en la selección intervienen distintos factores, sobre todo el contenido de la dispositio, variable, de cada uno de los testimonios. No obstante, ya se han apuntado también algunos paralelismos.

En definitiva, los hechos lingüísticos analizados muestran, en distinto grado, la continuidad del gallego en el registro escrito del corpus de Espinareda y prueban, como era de esperar, la existencia del continuo dialectal en el siglo xiII y el hecho de que las fronteras lingüísticas, las isoglosas, se difuminan entre las variedades lingüísticas en contacto. 


\section{Referencias bibliográficas}

Álvarez Maurín, María del Pilar. 1994. Diplomática asturleonesa. Terminología toponímica. León: Universidade de León.

Borrego Nieto, Julio. 2007. Leonés. En Manuel Alvar (dir.), Manual de dialectología hispánica. El español de España. 139-158. Barcelona: Ariel Lingüística (4. ${ }^{a}$ reimpresión).

Burón Castro, Taurino (ed.). 1998. Colección documental del monasterio de Gradefes, I (1054-1299). León: Centro de Estudios e Investigación San Isidoro / Caja Espańa de Inversiones / Archivo Histórico Diocesano (Colección Fuentes y Estudios de Historia Leonesa, n. ${ }^{\circ} 71$ ).

Cano González, Ana M. ${ }^{a}$ 1998. "Lasturianu n’El Bierzu. A propósitu del ALBP', Lletres Asturianes 69, 7-25.

Carrasco, Pilar. 1987. Fuero de Zamora. Estudio lingüistico. Málaga / Salamanca: Universidad de Málaga / Universidad de Salamanca / Colegio Universitario de Zamora.

Carrasco, Pilar \& Inés Carrasco. 1997. Estudio léxico-semántico de los fueros leoneses de Zamora, Salamanca, Ledesma y Alba de Tormes. Concordancias lematizadas. Granada: Universidad de Granada, 2 vols.

Casado Lobato, María Concepción (ed.). 1983. Colección diplomática del monasterio de Carrizo (León). León: Centro de Estudios e Investigación San Isidoro / Caja España de Inversiones / Archivo Histórico Diocesano. (Colección Fuentes y Estudios de Historia Leonesa, nos 28 y 29).

Castro Antolín, Mariano Eloy. 1987. Ribas del Sil. Léxico y toponimia. Páramo del Sil: Consejería de Educación y Cultura de Castilla y León, D.L.

$C D H=$ Instituto de Investigación Rafael Lapesa de la Real Academia Española. 2013. Corpus del Nuevo diccionario histórico (CDH), http://web.frl.es/CNDHE (13/01/2019).

Corriente, Federico. 2008. Dictionary of Arabic and. Allied Loanwords. Spanish, Portuguese, Catalan, Galician and Kindred Dialects. Leiden-Boston: Brill.

DALLA = Diccionariu de la Llingua Asturiana, https://www.academiadelallingua.com/diccionariu/ $(18 / 11 / 2018)$.

DCECH = Corominas, Joan y José Antonio Pascual. 2012 / 1980-1991. Diccionario crítico etimológico castellano e hispánico, CD-Rom. Madrid: Gredos.

$D d D$ = Ernesto González Seoane (coord.), María Álvarez de la Granja \& Ana Isabel Bullón Agrelo. 2006-2012. Dicionário de dicionários do galego medieval-Corpus lexicográfico medieval da língua galega. Instituto da Língua Galega. http://sli.uvigo.es/DDGM (22/10/2018).

$D E D A$ = Sánchez González de Herrero, M. ${ }^{a}$ Nieves (dir.). 2000. Diccionario español de documentos alfonsies. Madrid: Arco Libros.

Díez de Revenga, Pilar. 2001. Innovación y tradición en las lenguas de especialidad: el ejemplo de la lengua jurídica. En María Bargalló, Esther Forgas, Cecilio Garriga, Ana Rubio \& Johannes Schnitzer (eds.), Las lenguas de especialidad y su didáctica. 103-112. Tarragona: Universitat Rovira y Virgili.

DIGALEGO = Dicionario Galego, https://digalego.xunta.gal/digalego/Html/index.php (10/06/2018).

DPLD = Dicionário Priberam da Lingua Portuguesa, https://dicionario.priberam.org/ (13/01/2019).

DRAG = Dicionario da Real Academia Galega. 2012. https://academia.gal/dicionario (06/11/2018). 
Dubert García, Francisco. 2018. Contínuum xeolectal constitutivo no noroeste da Península Ibérica. Presentación para el Congresso Internacional em Variação Lingüistica nas Linguas Românicas, 2-4 de Maio de 2018, Universidade de Aveiro.

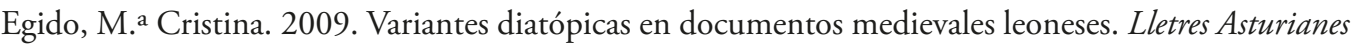
$101,23-44$

Fernández Rei, Francisco. 2002. O Galego do Bierzo e a súa situación actual. Boletín da Real Academia Galega 363, 327-353. https://academia.gal/boletins-web/paxinas.do?id=3349 (06/11/2018).

Fernández Rei, Francisco. 2015. Atlas Lingüistico Galego. Vol. VI Léxico. Terra, prantas e árbores. A Coruña / Santiago de Compostela: Fundación Barrié / Universidade de Santiago de Compostela.

Fernández Rei, Francisco, Emilo Xose Ínsua López \& Luís Rei. 2005. Fálame de barcos. Apontamentos para un catálogo (I). Ardentía. Revista Galega de Cultura Marítima e Fluvial 2, 11-17. https:// culturmar.org/publicacion/ardentia-2/\#page/6 (9/4/2019).

Ferreira da Silva, Jaime \& Paulo Osorio. 2008. Introdução à História da Lingua Portuguesa dos factores externos à dinâmica do sistema linguïstico. Chamusca: Ediçoes Cosmos.

García Arias, Xosé Lluis. 1995. Asturianische und leonesische Skriptae / Las scriptas asturianas y leonesas. En Lexikon für Romanistische Linguistik, II, 2. 621-662 Tübingen: Max Niemeyer. [Reedición (2002): "La escritura medieval asturiana", en Informe sobre la llingua asturiana. 59-68. Uviéu: Academia de la Llingua Asturiana].

García Gondar, Francisco. 1978. O infinitivo conxugado en galego. Santiago de Compostela: Universidade de Santiago de Compostela.

García Martín, José María. 2008. Relaciones entre los estados peninsulares y significado de las lenguas en la Baja Edad Media. En Javier Elvira, Inés Fernández-Ordóñez, Javier García González \& Ana Serradilla Castaño (eds.), Lenguas, reinos y dialectos en la Edad Media ibérica. La construcción de la identidad. Homenaje a Juan Ramón Lodares. 31-62. Madrid / Frankfurt: Iberoamericana / Vervuert.

García Rey, Verardo. 1979. Vocabulario del Bierzo. León: Nebrija.

García y García, Jesús. 1997. Los límites históricos entre el gallego y el asturiano-leonés en el Bierzo. Lletres Asturianes 64, 7-20.

GLOSSA = Glosario da poesía medieval profana galego-portuguesa, http://glossa.gal/glosario (11/01/2019).

Jiménez Suárez, María Jesús. 2005. Colección Documental del Monasterio de San Andrés de Espinareda (1043-1428). León: Centro de Estudios e Investigación San Isidoro / Caja Espańa de Inversiones / Archivo Histórico Diocesano (Colección Fuentes y Estudios de Historia Leonesa, no 107).

Krüger, Fritz. 1947. Léxico rural del noroeste ibérico. Madrid: Instituto Antonio de Nebrija (CSIC). (Traducción de Emilio Lorenzo y Criado).

Lagüens, Vicente. 1992. Semántica jurídica: binomios léxicos en la prosa notarial. En Actas del II Congreso Internacional de Lengua Española. 1121-1128. Madrid: Pabellón de la Lengua Española.

Le Men, Jeannick. 1996-. Repertorio de léxico leonés. http://www.gruposincom.es/repertorio-de-lexico-leones?utm_source=feedburner\&utm_medium=email\&utm_campaign=Feed $\% 3 \mathrm{~A}+$ sincom+\%28SinCom\%29(11/01/2019).

Lleal Galcerán, Coloma. 1990. La formación de las lenguas romances peninsulares. Barcelona: Barcanova.

Lorenzo González, Guillermo. 2016. ¿Por qué no en asturiano? El infinitivo flexionado como «apomorfia negativa» de la lengua asturiana. Lletres Asturianes 114, 39-58. 
Marcet Rodríguez, Vicente J. 2001. La frontera lingüística del Bierzo. En José Antonio Bartol Hernández, Salvador Crespo Matellán, Carmen Fernández Juncal, Carmen Pensado Ruiz, Emilio Prieto de los Mozos \& Ma Nieves Sánchez González de Herrero (eds.), Nuevas aportaciones al estudio de la lengua española. Investigaciones filológicas. 265-275. Salamanca: Luso-Española de Ediciones.

Marcet Rodríguez, Vicente J. 2002. Pervivencia de rasgos leoneses en el Atlas Lingüístico de Castilla y León y en el Atlas Lingüistico de El Bierzo. Interlingüistica 13 (II), 441-454.

Marcet Rodríguez, Vicente J. 2007. El sistema consonántico del leonés: peculiaridades fonéticas y usos gráficos en la documentación notarial del siglo XIII. Salamanca: Ediciones Universidad de Salamanca.

Méndez Fernández, Luz. 2016. O Tumbo das viñas de Ribadavia: Estudo histórico e lingüistico. (Tesis doctoral dirigida por Ana Isabel Boullón Agrelo (codir. tes.), Ramón Lorenzo Vázquez (codir. tes.). Universidade de Santiago de Compostela).

Morala Rodríguez, José Ramón. 2004. Del leonés al castellano. En Rafael Cano (coord.), Historia de la lengua española. 555-569. Barcelona: Ariel.

Moreno Fernández, Francisco. 2005. Historia social de las lenguas de España. Barcelona: Ariel.

Pensado Tomé, José Luís. 1983. El léxico hispánico occidental en el Tumbo viejo de San Pedro de Montes. Verba: Anuario galego de filoloxia 10, 43-78.

Pérez Rodríguez, Estrella. 2011. El léxico de los textos asturleoneses (s. viII-1230): valoración. En José Martínez Gázquez, Óscar de la Cruz Palma \& Cándida Ferrero Hernández (coords.), Estudios de Latín Medieval Hispánico. 935-957. Firenze: SISMEL.

Sánchez González de Herrero, María de las Nieves. 2003. Léxico de los documentos alfonsíes dirigidos a Álava, Navarra y Guipúzcoa. Príncipe de Viana 64 (229), 455-469.

Sánchez González de Herrero, María de las Nieves. 2005. El léxico de los documentos alfonsíes. Estudis romànics $27,41-72$.

Sánchez Prieto-Borja, Pedro. 2004. La normalización del castellano escrito en el siglo XIII. Los caracteres de la lengua: grafías y fonemas. En Rafael Cano (coord.), Historia de la lengua española. 423-448. Barcelona: Ariel.

Santa Rosa de Vitervo, Joaquim de. 1865. Elucidario das palavras, termos e frases que em Portugal antigamente se usaram e que hoje regularmente se ignoram: obra indispensavel para entender sem erro os documentos mais raros e preciosos que entre nós se conservam. Lisboa: A. J. Fernandes Lopes.

Saralegui, Carmen \& Carmela Pérez-Salazar. 1992. Coordinación de sinónimos en textos jurídicos. RILCE, Revista de Filología Hispánica 8, 1, 112-133.

Seco Orosa, Ana. 2001. Determinación da fronteira lingüística entre o galego e o leonés nas provincias de León e Zamora. Revista de Filología Románica 18, 73-102.

Serrano, Luciano. 1906. Fuentes para la historia de Castilla. Tomo I. Colección Diplomática de San Salvador de El Moral. https://bibliotecadigital.jcyl.es/es/consulta/registro.cmd?id=19292 (14/11/2019).

Souto Cabo, José Antonio. 2008. Do latin ao galego(-portugués): tempos, modos e espazos para una mudanza escritural na documentazón notarial galega do séc. XIII. En Javier Elvira, Inés Fernández-Ordóńez, Javier García González \& Ana Serradilla Castaño (eds.), Lenguas, reinos y dialectos en la Edad Media ibérica. La construcción de la identidad. Homenaje a Juan Ramón Lodares. 167-190. Madrid / Frankfurt: Iberoamericana / Vervuert.

TLPGP = Álvarez, Rosario (coord.): Tesouro do léxico patrimonial galego e portugués. Santiago de Compostela: Instituto da Lingua Galega. http://ilg.usc.es/Tesouro (15/11/2018). 
TMILG = Varela Barreiro, Xavier (dir.). 2004-. Tesouro Medieval Informatizado da Lingua Galega. Santiago de Compostela: Instituto da Lingua Galega, http://ilg.usc.es/tmilg (30/11/2018).

Torrens Álvarez, María Jesús. 2013. Sobre la apuesta por la escritura romance en los monasterios burgaleses: Oña vs. Las Huelgas. Cuadernos del Instituto de Historia de la Lengua 8, 321-342.

Varela Sieiro, Xaime. 2003. Léxico cotián na Alta Idade Media de Galicia. O enxoval. Coruña: Seminario de Estudos Galegos.

Varela Sieiro, Xaime. 2008. Léxico cotián na Alta Idade Media de Galicia: a arquitectura civil. Santiago de Compostela: Universidade de Santiago de Compostela.

Vázquez Diéguez, Ignacio. 2018. Mudanças fonético-fonológicas do latim para o portugués, galego e espanhol: um confronto. En Paulo Osório (ed.), Lingüistica Histórica e História do Português. Das Origens ao Século XVI. 127-141. Salamanca: Luso-Española de Ediciones. 